\title{
The "Senso-Math" Preschool Mathematics Program, Facilitator Training and Their Contribution to the Preschool
}

\author{
Dina Hassidov \\ Western Galilee College, Akko, Israel \\ Shaanan Academic Teachers' College
}

\begin{abstract}
The "Senso-Math" program promotes early childhood mathematical knowledge in preschools. This paper reports on the rationale behind the development of the program, gives a description of the activities and process of the program, and describes the training of special trained facilitators who visit preschools to present the program to the children and thus foster a love and knowledge of basic mathematical concepts.

The paper then gives a report of a five-year study that followed 500 "Senso-Math" facilitators during their training and subsequent teaching experience in the preschool alongside regular preschool teachers. These 500 facilitators activated 10,000 three-to-sixyear-old children in various demographic sectors (Jewish Orthodox, Jewish immigrants from the Caucasus, and Druze).Forty-nine were interviewed in depth to examine their professional development, including their change in attitude to mathematical education in preschool, and to assess the contribution the program makes to preschool mathematics education. The results of the study indicate that, overall, the program contributed to a positive trend in their attitude regarding preschool mathematics education, although there were significant differences in attitude among the various demographic sectors studied.
\end{abstract}

\section{Introduction}

The global trend today is to favor access to mathematics at increasingly younger ages. In essence, children are daily engaged in mathematics from birth [1], and the modern approach is that preschool math practice should develop that early awareness so as to cultivate mathematical thinking at an early age. Studies have shown that preschool children have the ability to build concrete mathematical, sometimes even abstract, processes, and that the earlier that children are exposed to the experience, the greater the child's mathematical development later [2]. Indeed, preschool math practice helps in shaping the child's future cognition, mathematical thinking, general thinking, and cognitive abilities [3]. Studies have also shown that the volume and quality of math practice during preschool predict a child's success in math in elementary school [4]. New teaching principles for mathematics include developing quantitative, critical and creative understanding, directing towards thinking and understanding, and encouraging mathematical discourse and metacognitive processes [5].

Neuroscience research also demonstrates the importance of preschool math activity. Clements showed that the structure and organization of the brain of developing preschoolers is affected by their learning experience, and complex activities lead to increased brain development [6].

It is therefore clear that preschool professionals must be equipped with knowledge regarding teaching mathematics to preschoolers. Unfortunately, studies conducted in recent years indicate that teachers assigned with teaching mathematics in preschool find themselves facing difficulties and feelings of incapacity for the job. While this may stem from negative personal experiences vis-à-vis mathematics, it is certainly also based on a lack of professional knowledge due to the absence of appropriate mathematics-for-preschool training in college $[7,8,9]$.

Another factor affecting preschool learning is the learning environment, which has changed from the traditional one, where the teacher transmits knowledge, to the modern one where learning is active and constructivist [10]. In this new environment, the teacher serves more as a facilitator or mediator who encourages learning by enabling opportunities and interesting activities for the students to engage in, and the student takes on the responsibility for building their learning experience from the knowledge available. This change has led to a transformation in the teacher's role and responsibilities with its attendant difficulties.

Since teachers' attitudes influence children's attitudes towards mathematics $[11,12]$ it seems clear that overburdening preschool teachers with the additional task of creating and enabling positive experiences in foundation mathematics for young learners is counter-effective to the goals in question.

In light of this problem, educators realized the need to develop appropriate assistance programs to strengthen teachers' sense of competence regarding teaching mathematics in preschool.

In summary, the goals of the Senso-Math preschool program are as follows: 
1. To promote and enrich the mathematical knowledge of preschool children.

2. To train women to work as mathematics facilitators for children of preschool age.

3. To integrate these mathematics facilitators into preschool programs.

\section{The development of the "Senso-Math" program}

A child's mathematical development is generated early in life. Even before children set foot in elementary school, many have already acquired a wide, informal knowledge base of mathematical concepts. Everyday activities can instill in them mathematical ideas, thus helping them to develop more complex ideas on a meaningful level. Early childhood mathematical training is based on such a concept: developing children's intrinsic thinking skills and intuitive learning by creating an interesting, focused learning environment to foster mathematical development. When small groups of children are guided by specially trained adults whose role it is to mediate the surroundings so as to create for them a representational mathematical world, the children's mathematical development can be supported and encouraged, especially if they are allowed to work in a stimulating social situation that allows them individual attention while encouraging them to think, relate to others, develop language skills and face intellectual challenges.

Based on the understanding that a change was needed in teacher-training methods, and realizing the need for a comprehensive preschool mathematics program taking into account the unique character of preschool learning, the "Senso-Math" program was developed by D. Hassidov, M. Klugman, and J. Oberman. This team of educators sought to design an enrichment program beyond the regular instruction formally offered in the preschool. The professionalscientific group that developed the Senso-Math program are senior members of the educational profession with widespread, extensive educational experience in all stages of education-education in general, and mathematics in particular. They have years of experience in training educators and integrating them pedagogically into various educational frameworks.

The Senso-Math Preschool Mathematics program was designed for children aged 3-6 years of age. It is based on the current notion that everyone is born with intrinsic mathematical abilities that can be realized early on given the correct experience.

The Senso-Math Preschool Mathematics program was developed to be a unique program that familiarizes preschool children with the mathematical aspects of the world around them in fascinating and enjoyable ways. The facilitator visits the preschool once a week to encourage natural learning through experiential activities with specialized pedagogic materials that engage the different senses - touch, sight, hearing, etc. Using interesting, engaging objects from the child's immediate surroundings combined with focused mathematical content, the program provides a comprehensive learning experience that develops the child's curiosity and mathematical intuition in an enjoyable, unthreatening manner. The sessions also include motoric activities to allow the acquisition of knowledge also through movement.

Through the varied, challenging activities in the Senso-Math program, children receive a positive, successful experience in the world of mathematics and acquire a solid foundation in the basic math concepts required for formal learning. Having this, they can continue formal studies with the confidence necessary for future success in learning mathematics.

Alongside developing the pedagogical materials, one of the main goals was to train special "facilitators" who would supplement mathematics teaching in preschool. These facilitators would then be integrated into preschools or other areas of education.

\subsection{Program curriculum and contents}

The "Senso-Math" program is based upon the definition of the Israel Ministry of Education's new curriculum for mathematics in early childhood [2], and aims to give preschoolers the chance to experience math as it occurs in their daily world. It includes diverse and dynamic graded exercises and unique, specially developed learning materials that combine sensory and motoric activities. The activities develop sequentially throughout years, until kindergarten, preparing children for first grade.

Thirty teaching-learning sets were developed covering three learning styles (creative, structured, and daily environment) for each of the ten topics in the curriculum of the Israel Ministry of Education. The program aimed to cover three years of schooling (pre-nursery, nursery, and kindergarten), preparing the children for first grade mathematics. The specially designed activities and materials encourage transcription and reflective mathematical discourse and are intended to provide a rich mathematical learning environment and to assist the development of mathematical thinking. They were designed to allow teachers to custom-create activities based on the individual needs of their pupils.

A kit for each child was also developed; some of the material is intended to be sent home for activities involving the parents.

\subsection{Initial testing}

The pedagogical and mathematical rational of the "Senso-Math" teaching kits were initially tested in 
20 preschools and validated through observation, data collection, and accompanying research, then were revised to further enrich the curriculum framework. After final approval by the Israel Ministry of Education, several hundred preschools were chosen to integrate the program in facilitated preschool mathematical education.

\subsection{The contribution that the Senso-Math group can have on the success of the program}

The Senso-Math program is based on wide educational experience of the professional-scientific group that developed the Senso-Math program. The members of the group also have many years of experience in promoting programs and projects connected to various educational systems, including teaching mathematics in all grades and to all ages of children in formal and informal classes in Israel; in developing mathematical programs and instructional materials; and in managing and promoting formal and informal educational systems. The experience was accumulated in the country's universities, teachers' colleges, and development centers under the auspices of the Ministry of Education or other administrative bodies. The vast experience of the group gives them the ability to successfully develop and promote the Senso-Math program in preschools with great success and to achieve the objectives of the program.

\section{How the "Senso-Math" program works}

The program operates as follows. A professional facilitator visits the preschool once a week, where she works with groups of 8-10 children at a time, leading them through a 40-to-45-minute session of enjoyable activities using materials and ideas that invite mathematical exploration and learning in an experiential, multi-sensory, dynamic way. The activities relate to mathematical problems from everyday life, or with the topics concurrently taught in the school (holidays, daily routines, etc.). Mathematical concepts covered include counting, numbers recognition, ordering numbers, comparing numbers, sorting, combining and dividing, adding and subtracting, patterns and templates, geometrical shapes and spatial sense, organizing data, describing data graphically, and measurement, and match with the Department of Education suggestions for prerequisites for first grade.

The facilitator encourages the children to think about the activity and express themselves orally. By experiencing these activities in a personal way, the child has a chance to assimilate what he has learned and build a firm, base of mathematical concepts and basic operations.

Groups are small enough so that each child has receives individual attention and has the opportunity to express himself. The child can also work independently without losing the support or missing the feedback from the group. The 40 minute time period is the most effective for early childhood learning.

Materials: The content of the program is comprised of approximately 30 learning units. The learning material is found in the "mathematical learning center" that the facilitator brings with her, in the individual "First Fruits" kits that are furnished for each child, or in the "Curiosity Box" that remains in the preschool all year. The facilitator's kit includes teaching guides for her and learning material for the children. The children's kits include individual items that the child can use according the facilitator's instructions. Some of the material offered in the children's kit is designated to be used at home with the parents.

At the end of each unit, the children take home a page for their parents with a summary of what they have learnt and suggestions for additional activities.

\section{Facilitator training}

Five hundred women took part in the initial facilitator training program. They were academicand college-educated, and their suitability for the program was determined through personal interviews and appropriate certification. Training took place throughout the country in groups of up to 25.

Each participant attended 128 academic hours in over 20 sessions that spanned two years. Forty hours of training focused on integrating administratively into the preschool, and 88 hours of content training focused on mathematical education in early childhood and hands-on experimentation and application of the "Senso-Math" program in preschools. A “Senso-Math” “moderator's kit” was used during the facilitators' training as a center of activity. The content training included several areas: methods of teaching and learning, mathematical education, and cognitive abilities of preschool children, based on the premise that the program will work better if the theoretical concepts behind it are clear to the teacher. Modeling and demonstrations showed the facilitators how to coach preschool teachers in teaching mathematics.

Part of the training included practical experience in preschools. Each facilitator received 15 hours of one-on-one professional guidance at the beginning of the practical work in the class.

The topics covered included methods of teaching and learning, mathematics education, cognitive abilities of preschool children, early childhood development, music, movement, storytelling, puppet shows, and more. During the course, participants were taught how to use the special kit that provides a mathematical activity center in the preschool. The 
kits are the facilitator's toolbox and include equipment and other items to teach the 30 topics covered in the program. (These activities coordinate with the range of topics taught in the preschool throughout the years, merging them with the mathematical topics required for basic knowledge in preparation for learning mathematics in school.)

Upon completion of the course, the women were qualified to work independently to promote and enrich preschoolers in math.

\section{Training program (summary)}

1. Locating qualified women who can become facilitators in the areas where training is to take place.

2. Training facilitator in the scope of 128 hours for two years.

3. Placement in kindergarten.

4. Assistance and accompanying the facilitator during the work as facilitator for 15 hours each.

These guidelines include complete descriptions of the fonts, spacing, and related information for producing your proceedings manuscripts. Please follow them.

\section{Integration into preschools}

\subsection{Options for activities for mathematics facilitators in preschools}

The facilitators of the Senso-Math program have two options for working in the program.

1. Preschool option: Here, the facilitator works in the formal preschool environment, visiting each preschool once a week for 30 meetings throughout the academic year and according to the general description above (30-40 minutes per meeting, with groups of 10-15 children at a time). The children will be divided into learning groups based on the recommendations of the preschool teacher. The activity takes place using the facilitator's educational kit and the individual student kits that each of the children in the program receives. A similar option is boarding schools or preschools that open their doors for afternoon activities.

2. The informal education option: Here, the Senso-Math facilitator must take the initiative to organize small groups of children (about 10 per group) of ages between 3-6 years in community centers or private afterschool classes. The children will learn once or twice a week for 40 minutes each time. The children must purchase a study kit with the accessories, games and various items that the child will use throughout the year. The facilitator schedules the meetings to suit the place where they take place. In these frameworks, parents can be invited to participate.
The pedagogical rationale for operating a SensoMath program in the preschool is that Senso-Math facilitators who offer the program to the preschool must know to market her product and convince the preschool teacher, the authorities, and the parents of the value the program has in contributing to the readiness of the children for mathematical learning in school. Every child will learn within the framework described above once or twice a week in the preschool or in afternoon enrichment programs.

\subsection{The reasons for integration Senso-Math facilitators to teach mathematics in the preschool}

An argument that often comes up regarding specially trained facilitators to promote mathematics education is "Why can't the regular preschool teacher to it?"

The regular preschool teacher is, in effect, the director-administrator of an educational organization and also a pedagogical leader promoting learning, which in itself is a complex process. The preschool teacher has been trained for her position in education colleges and must have an academic degree. She has received knowledge in management and teamwork in addition to her pedagogic knowledge, and is guided by the inspector and professional trainers.

The preschool teacher spends much time directing and coordinating the activities of her team, which includes teachers' aides, substitute teachers, teachers on call, and teachers who offer special help to new immigrant and children with special education requirements, along with other auxiliary manpower such as psychological services, social workers, and more. Being an administrator, she also has to deal with such things as planning a budget and coordinating between the various teaching auxiliaries that visit the school.

Pedagogically, the preschool teacher is responsible for translating the educational policies of her district and local inspector and organizing the educational environment according to the policies of the Ministry of Education, keeping in mind her own specific "clients" and her personal pedagogical beliefs. In this framework, she must allocate longand short-term goals, plan an annual curriculum, analyze the alternatives, devise lesson plans, and organize meeting with staff, parents and other stakeholders throughout the year. She determines the educational content that will be used throughout the year and how the assistant teacher's aides will divide the many and various tasks.

It can be seen that "merely" being a preschool teacher and facilitator of learning entails much effort and responsibility and it can be assumed that a substantial proportion of preschool teachers would have difficulty being a quality teacher of mathematics alongside their role as educational 
administrator of a very active organization. Furthermore, despite extensive training in preschool pedagogy, the preschool teacher does not necessarily possess a deep understanding of mathematical education by the preschool teacher.

In fact, teaching mathematics is a specialized job that requires skills and knowledge that the regular preschool teacher does not have. In order to encourage mathematics learning in the preschool, the teacher must know how to encourage free play while learning mathematics and to plan an environment that will encourage mathematical investigation with illustrative and investigative tools and accessories. The children's play with these items form a large part of the basis that learning the required pre-math concepts require.

Therefore, when the children are playing in a guided environment, the teacher needs to be able to observe the children and intervene when necessary. She needs to have the expertise to know if intervention is necessary (if mathematical thinking is developing) or not (if mathematical thinking is being inhibited). Later she must know how to discuss the experience with the children, either individually or as a group, in order to enrich the process that they went through.

For example, if two children are arguing about who has the "bigger" tower of blocks, the teacher may discover that one of the children is referring to the height, yet the other is talking about the width, area or volume. The teacher must point out that the two structures are bigger in different ways and ask the children what they see. Later, she should conduct a discussion with the children about this idea as she presents it as an interesting occurrence.

Besides having the skills required to foster mathematical learning, she must also invest a lot of time in furnishing the classroom with appropriate materials and devising lesson plans, time that, clearly, she does not have.

The reasons above all justify the integration of specially trained Senso-Math facilitators to teach mathematics in the preschool.

\section{Study of facilitators' experiences and attitudes}

During the initial development of the program, 500 women were chosen to undergo training as facilitators and integrate into the preschool system, and a study of the experiences and attitudes of 49 of them was undertaken to focus on the influence of the "Senso-Math" program on them in order to assess the worthiness of the program from the viewpoint of the participants themselves.

In particular, we intended to study the following points:

1. Participants' motivation to work
2. Participants' conviction of the necessity of mathematics learning in preschool

3. Participants' confidence in teaching mathematics

4. Participants responsibility to their own professional development

5. The extent to which the program gives facilitators appropriate tools and means for preschool mathematics teaching

6. Differences in attitude of participants from different socio-economic groups

7. Effects of the program on mathematics instruction in the preschool, and the teachers' attitudes to it.

\subsection{Population}

Of the 500 participants in the "Senso-Math" program, 49 were chosen (randomly) to take part in this study. Each participant had a diploma or training certificate from a teachers' college or other school of higher education (average years of education was 14.5), and were mathematically oriented and with the ability to work as mathematical facilitators in preschool. Although they all had background in early childhood education, none of the participants had ever worked in preschool education.

The average age was 34 years old $(\mathrm{SD}=8.48$ ). The women were of heterogeneous marital status (38 married, 5 single, 6 divorced/separated), with an average of 2.55 children. They came from diverse socio-economic and demographic sectors from around the country: 15 were orthodox Jewish from the center of Israel, 15 were secular new immigrants from the Caucasus living in Haifa, and 19 were Druze from Galilee area.

\subsection{Research tools}

Research methods were both quantitative and qualitative. Data collection was performed at three times: before the training course began, at the completion of the course, and a year later. Data were collected via a questionnaire that had been written by the researchers and interviews. Fifteen facilitators (who were not included in the study group) validated the questionnaires.

The questionnaire included 22 statements to ascertain the participants' attitudes to teaching mathematics in preschool and to the "Senso-Math" training program. The statements were rated from 1 (very great extent) to 5 (not at all). Negative statements have been marked.

After filling in the questionnaires, semi-structured interviews were conducted with the study participants to clarify their approach to the statements on the questionnaire. Relevant background information was also collected at this 
time (age, education, place of residence, occupation, socioeconomic status, etc.).

The final interview (a year after completion of the program) also assessed the employment status of the participants to evaluate the long-term benefits of the program.

\subsection{Questionnaire}

The 22 statements were divided as follows.

Statements about attitudes toward learning mathematics: It is important that children start learning mathematics in preschool; Children of preschool age can learn mathematics; If the basics of mathematics are learned before first grade, the child will develop a positive attitude towards the subject; Anyone can learn mathematics; Anyone can enjoy learning mathematics.

Statements about professional confidence: Anyone who aspires to succeed can do it at any age; Unemployed women should be concerned about their professional development; Teaching mathematics in preschool requires readiness, knowledge, and professional maturity; The training gave me professional confidence; The training encouraged me to pursue my professional aspirations; I am considering making mathematics teaching my main profession.

Statements about self-confidence in teaching mathematics: The training gave me confidence to teach mathematics; The training encouraged me to start teaching mathematics in preschool; I see my future in teaching children mathematics; I feel I can incorporate the "Senso-Math" program into the preschool; Had I not participated in the "SensoMath" program, I would not have confidence to teach mathematics.

Statements about evaluation of the program: The "Senso-Math" facilitators' kit helped me in mathematical guidance in the preschool; The "SensoMath" activity pages helped me in mathematical facilitation in the preschool; The course was conducted professionally; The training gave me tools to facilitate mathematics in preschool; The training gave me tools to teach mathematics in preschool; I would recommend participating in the "Senso-Math" program to a friend.

\subsection{Results}

6.3.1. Employment status at the beginning, at the end and a year after the study. One aim of the study was to assess whether participation in the program helped participants find employment. At the end of the study, $69 \%$ of the subjects were working compared with $66 \%$ at the beginning of the study. A year later, $75 \%$ were working, of them $10 \%$ of them in the "Senso-Math" program and the rest in other educational fields. However, according to average scores, it cannot be unequivocally concluded that participating in the training will encourage women to try to fulfill professional ambitions and concentrate on teaching mathematics.

6.3.2. Different attitudes between married and unmarried participants. A second aspect was to examine the differences in attitudes between married and unmarried participants. Statistical studies revealed that marital status did not significantly affect attitude either toward the "Senso-Math" program or the notion that math should be taught in preschool. In fact, most of the participants agreed that math should be taught in preschool.

6.3.3. Attitudes toward teaching mathematics. The average rating of the statements pertaining to the participants' attitude to teaching mathematics was close to 4 and above, indicating that most thought that preschool mathematics education was important (average 4.65), that they had developed a positive attitude to the profession (average 4.51), and that they believed that anyone can learn math (average 4.15). As can be seen in Figure 1, the statement that received the highest average score is "It is important that children start learning mathematics in preschool" (average 4.65), while the least important statement is "Anyone can enjoy learning mathematics” (average 3.88).

\subsubsection{Developing professional confidence.}

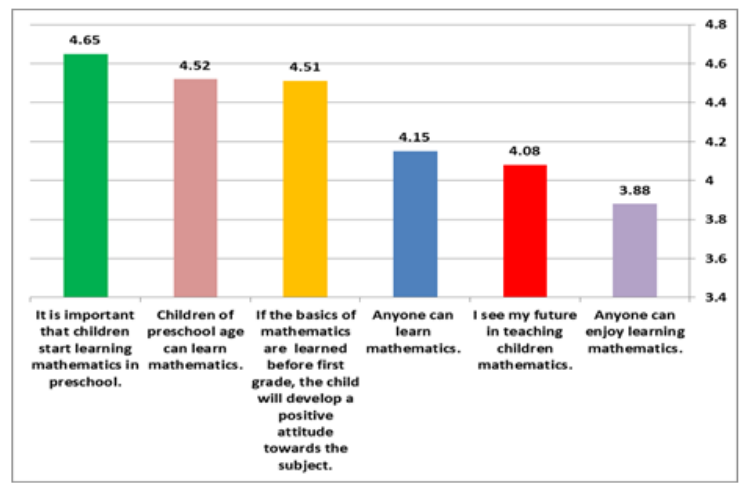

Figure 1. Attitudes of participants towards learning mathematics

Regarding statements about professional confidence, the statement that received the highest average score was "Anyone who aspires to succeed can do it at any age" (average 4.40), whereas the statement "I am considering making mathematics teaching my main profession” received the lowest score (average 2.45). This suggests that the training encouraged the facilitators to begin teaching mathematics in preschool (average 3.67), gave them the ability to integrate the "Senso-Math" program into the preschool (average 3.57), and made them appreciate that teaching preschool requires readiness, 
knowledge and professional maturity (average 3.79). Statements reflecting average self-confidence and responsible approach to professional development ("Unemployed women should worry about their professional development.”) received a high average score. See Figure 2.

6.3.5. Self-confidence in teaching mathematics. An interesting anomaly showed up in the ratings of the statement "The training gave me confidence to teach mathematics" (average 3.17) which showed that the participants believed that the training gave them more confidence, compared to that of "Had I not participated in the 'Senso-Math' program, I would not have confidence to teach mathematics" (average 1.72), which shows the opposite trend (see Figure 3).

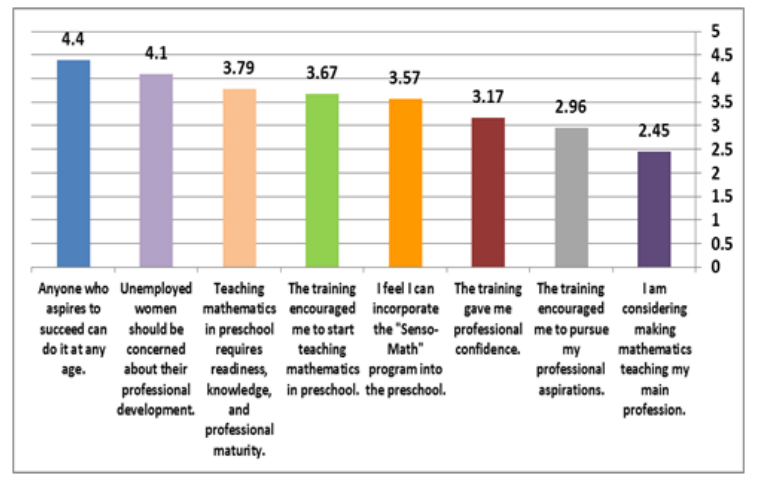

Figure 2: Professional development of participants

However, subsequent interviews with the participants revealed that they had misunderstood the question because it was a "negative statement" and therefore rated it incorrectly.

6.3.6. Program evaluation. The results indicated that the participants believed that the "Senso-Math" program and materials had value in considerably improving their ability to teach mathematics in preschool. In general, most of the statements relating to the program and accompanying kit won high scores-above 4. Participants showed satisfaction with the teaching tools that training gave them (average 4.15), with the training for guiding mathematics in preschools (average 4.18), with the teaching materials (average 4.19), and with the facilitator kits (average 4.30). They felt that the training was conducted professionally (average 4.19). Most indicated that they would recommend the program to a friend (average 3.96).

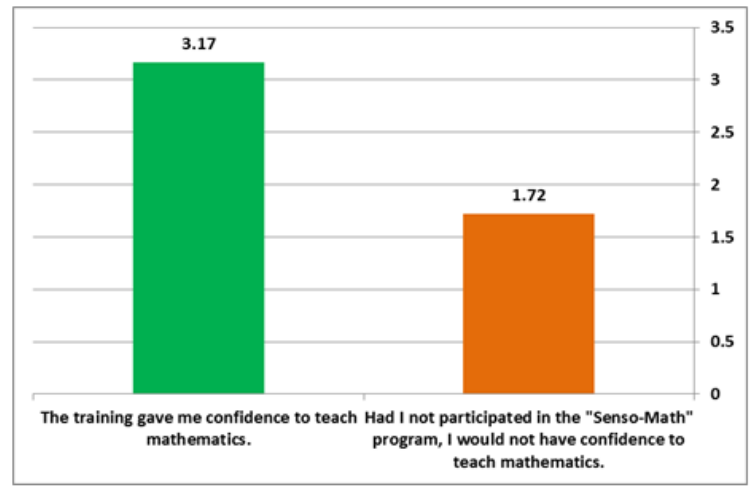

Figure 3. Self confidence in teaching mathematics of participants

6.3.7. Differences between participants. This study also aimed to investigate the difference in attitudes towards teaching mathematics between various groups of participants, taking into account demographics, employment status, age, education, and number of children. A comparison of the attitudes towards teaching mathematics between the sectors showed that Caucasians and Druze expressed a more positive attitude than the Jewish Orthodox participants. In addition, the highest satisfaction from the program was expressed by the new immigrants from the Caucasus (average 4.69), whereas the lowest satisfaction was expressed by the orthodox participants (average 3.36).

Regarding attitudes towards the "Senso-Math" program among employed and unemployed women, results indicated that there was no significant difference between them. (The statement regarding recommending the program to a friend was used to indicate the level of satisfaction from the program.)

Interestingly, results showed that the higher the education, the lower the satisfaction from the program was, the more negative the attitude towards the program was, and the less they believed in professional development. The qualitative findings support, strengthen, and clarify the quantitative findings.

This seems an interesting trend. Perhaps educated women are more critical in general, and this criticism is expressed by the attitudes they expressed towards the program.

6.3.8. Evaluation of facilitator presence in the preschool classroom. In addition to the questionnaires regarding the attitudes of the facilitators, an assessment was carried out to study changes that occurred in the preschools.

In preschools where facilitators were integrated, the mathematical learning environment become rich and diverse. Reports from both the facilitators and the preschool teachers indicated that the teachers benefited from a professional colleague (the facilitator) who came once or twice a week, and who had the responsibility for teaching mathematics to 
the children. Teachers received training in how to teach preschool math from the facilitators, but also learned by observing the facilitators' activities in the class (modeling). Facilitators reported that the teachers often observed their activities with the children and repeated them during the week when the facilitators were not in attendance.

The involvement of the facilitators also affected the teachers' attitudes towards teaching preschool mathematics. As one of the facilitators reported during her interview, "The teacher told me that since I had begun coming to the preschool, her attitude towards teaching mathematics changed. She told me that she is integrating daily mathematical activities into her program.”

The program also impressed upon the teachers the importance that professional understanding and training have on teaching mathematics to preschool children. One of the facilitators observed: "In the beginning, the teacher objected to having me in her preschool and teaching mathematics. After several months, though, we were collaborating nicely. The teacher told me that now she realizes that teaching mathematics in the preschool is a very important area and that $\mathrm{I}$, the facilitator, have received training that she lacks."

The introduction of facilitators into the preschools gave new prominence to mathematical instruction: because the facilitators were engaged for the express purpose of teaching mathematics, this aspect of preschool education became standard and not merely reduced to when the teacher found sufficient time to do so.

\subsection{Discussion and conclusion}

Changes in curriculum guidelines in Israel and abroad regarding the need for mathematics instruction in preschool imposes a heavy responsibility on preschool teachers. The "SensoMath” program, which was developed as an answer to this demand, offers resource material and specially trained facilitators to allow preschool children to experience math in a unique learning program.

This study showed that undergoing the facilitator training program led to a successful area of employment for participants, as the majority of those surveyed had, a year later, been successfully integrated into mathematics teaching in preschools, and indicated that the "Senso-Math" training had contributed to their professional development and given them confidence to facilitate mathematics teaching in preschool. Moreover, teaching mathematics in preschool became a key area of interest to them that was intriguing and challenging. Furthermore, they recognized that children should and can learn mathematics in preschool.

The study also indicated that once teachers and facilitators collaborate nicely, the addition of the facilitators in the preschool class becomes accepted as a positive contribution to the learning environment. The teachers realized that mathematics teaching is a profession in itself.

Finally, the study revealed that the training and the materials provided by the program were of a professional caliber that considerably contributed to the participants' - and, subsequently, to the preschool teachers' and children learners' success.

\section{References}

[1] National Association for the Education of Young Children (NAEYC) and the National Council of Teachers of Mathematics (NCTM). Early Childhood Mathematics: Promoting Good Beginnings. A joint position statement. (Last checked 27 April 2009)

http://www.naeyc.org/about/positions/pdf/psmath.pdf, 2002.

[2] Israel Ministry of Education. Curriculum for the Education of Mathematics in Early Childhood (Core Mathematics Program). The Department for the Development of School Curricula, Israel Ministry of Education,

http://cms.education.goc.il/EducationCMS/Units/Tochniyo t_Limudim/KdamYesodi, 2009.

[3] J. Baroody, "Does Mathematics Instruction for 3-to-5Years Olds Really Make Sense?” Young Children, 55(4), 2000, pp. 61-67.

[4] D. H. Clements, and J. Sarama, "The Young Child's Mathematical Mind”, Parent \& Child, October, 2006, pp. 30-37.

[5] National Council of Teachers of Mathematics (NCTM). Principles and Standards for School Mathematics. NCTM, Reston, VA, 2000.

[6] D. H. Clements, "Mathematics in the Preschool", Teaching Children Mathematics, 7(5), 2001, pp. 270-275.

[7] D. Tirosh, and O. A. Graeber, "Evoking Cognitive Conflict to Explore Pre-service Teachers' Thinking”, Journal for Research in Mathematics Education, 21(2), 1990, pp. 98-108.

[8] Ben-Yehuda, M. and B. Ilany, The Development of Mathematical Thinking in Young Children: Theory, Research and Practice in Training Teachers, Machon Mofet Publications, Tel Aviv, Israel, 2008 (in Hebrew).

[9] Y. Guo, L. M. Justice, B. Sawyer, and V. Tompkins, “Exploring Factors Related to Preschool Teachers' SelfEfficacy, Teaching and Teacher Education, International Journal of Research and Studies, 27 (5), 2011, pp. 961968.

[10] P. Cobb, Accounting for Mathematical Learning in Social Context of the Classroom. An invited address presented at ICME 8, Seville, Spain, 1996. 
[11] G. N. Philippou, and C. Christou, "The Effects of a Preparatory Mathematics Program in Changing Prospective Teachers' Attitudes towards Mathematics", Educational Studies in Mathematics, 35, 1998, pp. 189206.

[12] J. Plucker, "Secondary Science and Mathematics Teachers and Gender Equity: Attitudes and Attempted Interventions", Journal of Research in Science Teaching, 33, 1996, pp. 737-751. 